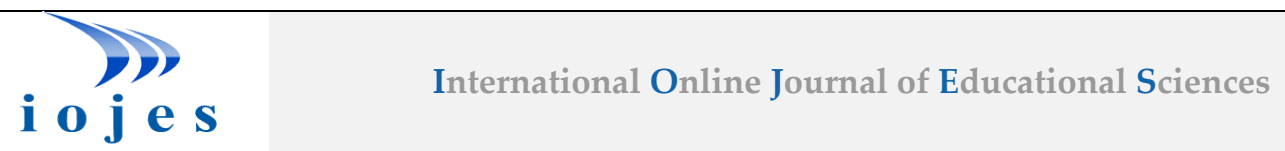

\title{
Examination of the Relationship Between Pre-service Teachers' Attitudes Towards Learning and Sustainable Learning Levels
}

\section{Research Article}

\section{Ismail EROL ${ }^{1}$, Semih CAYAK ${ }^{2}$}

${ }^{1}$ Namık Kemal University, Vocational School of Health Services, Department of Child Development, Tekirdağ, Turkey, ORCID: 0000-0001-85316001

${ }^{2}$ Ministry of National Education, Istanbul, Turkey, ORCID: 0000-0003-4360-4288

To cite this article: Erol, I., \& Cayak, S. (2021). Examination of the relationship between pre-service teachers' attitudes towards learning and sustainable learning levels, International Online Journal of Educational Sciences, 13(4), 1143-1151.

\begin{tabular}{ll} 
ARTICLE INFO & ABSTRACT \\
\hline Article History: & In this study, relationship between pre-service teachers' attitudes towards learning and sustainable \\
& learning levels are examined. Sample of the study consists of 428 pre-service teachers studying at \\
Received: 18.02.2021 & Tekirdag Namik Kemal University. Scale for Attitudes Towards Learning and Scale for Sustainable \\
& Learning were used throughout the study. Data obtained during the study were analyzed by \\
Available online: & arithmetic average, standard deviation, correlation analysis and regression analysis. According to \\
02.09 .2021 & findings, it is determined that pre-service teachers' attitudes towards learning and sustainable \\
& learning levels are at high levels. At the end of conducted regression analysis, it is found that scores \\
& obtained by means of scale for pre-service teachers' attitudes towards learning predict scores \\
& belonging to both cognitive and behavioral sub-scales of sustainable learning scale at a remarkable \\
& accuracy. Obtained findings are discussed in accord with relevant literature and suggestions were \\
presented.
\end{tabular}

(ㄷ) 2021 IOJES. All rights reserved

Keywords:

Learning, Attitude, Sustainable Learning, Pre-Service Teacher

\section{Introduction}

In today's world, where current knowledge accumulation is increasing very rapidly in parallel with developments in technology, any information produced in any place can spread to all parts of the world in a very short time due to globalization. This situation forces a modern person to constantly improve himself/herself. Otherwise, it is inevitable that people, who do not improve or update themselves shall be negatively affected both in their daily lives and in their professional careers. In order not to encounter such a

${ }^{1}$ Corresponding author's address: Namık Kemal Üniversitesi

Telephone: +905464221588

e-mail: ismailerol@nku.edu.tr

DOI: https://doi.org/10.15345/iojes.2021.04.013 
situation, it is important that individuals should always be open to learning, in other words, they should adopt a sustainable understanding of learning.

Learning has an important place in human life. In a globalized world, students are expected to learn a lot of knowledge under scope of formal education, starting from early childhood education to higher education (Dash \& Mohan, 2017). In the literature on learning concepts, which occupies such an important place in human life, there are not any comprehensive definitions of learning that researchers agree on. It is believed that learning is a multidimensional concept and that there are many factors that affect learning. When we consider different definitions made in the literature about learning; it is possible to briefly define learning as the exposure of behaviours to permanent changes as a result of environmental factors and experiences (Domjan 2004, p. 6). In other words, learning, as a phenomenon that continues throughout a person's entire life (Senemoglu, 2012), can be called as the sum of activities that people conduct. These activities are reflecting, feeling, thinking and doing; and it is believed that people develop special preferences and abilities to perform these activities (Kolb, 1981).

One of the elements that are effective in learning process is the attitudes of individuals towards learning. Attitudes are expressed as psychological processes involving positive or negative evaluations that individuals develop towards life happening around them (Chang \& Chang, 2013). Realization of successful educational practices in an education system depends on determining students' attitudes towards learning and designing educational environments for these attitudes (Pashler, McDaniel, Rohrer \& Bjork, 2008). According to these conclusions, it can be said that it is very difficult to train teachers, who shall educate people from the era of technology and the global era through traditional transfer of knowledge (Pehlivan, 2010). Especially in today's modern understanding of education, educators began to accept individual differences between students and turned out to be guides leading students in their journey towards knowledge, rather than offering knowledge to those, who are studying. From this point of view, individuals' attitudes towards learning became gradually important in accessing knowledge. Because positive attitudes to be developped for learning shall ensure that students are constantly open to learning and shall positively affect behavioural trends in this direction (Çetin \& Çetin, 2019). Studies conducted in this area indicate that attitude towards learning is affected (Yang \& Farn, 2005, s. 921) by many factors such as learners' perception of self efficacy (Salami, 2010), motivation (Marton \& Saljo, 1997) and burnout conditions (Orhan \& Komşu, 2016) and at the same time it affects many conditions such as job satisfaction (Orhan \& Komşu, 2016), academic success (Kazazoğlu, 2013) participation in learning (Anghelache, 2013) and constancy in learning (Samuelsson \& Park, 2017; Zhu, Zhang, Au \& Yates, 2020).

Sustainability is one of the concepts that became important in the last century and there are many studies often conducted on this topic (Johnston et. taken., 2007). Although sustainability was a concept that mainly included issues such as environmental protection, economic and social development when it was first introduced (Kuşat, 2012), it is now a concept that is often used in almost every field. In the most general sense, sustainability can be defined as an innovation's or application's being long term and corporate (Balc1, 2010). From a learning perspective, the concept of sustainability can be explained as the continuation of learning activity throughout a person's life, its not being interrupted, and person's realization of efficient learning by using what he/she has learned in different ways when necessary. Because in the last century, which is full of developments in science and technology that are hard to be followed, it is hardly possible to say that the information that individuals acquire in school may be sufficient to keep up with this rapid change. Therefore, this situation shall make sustainable learners successful in their profession and happy in their lives in the future. In this context, a person, who improves his ability to learn at every opportunity, gains a sustainable learning ability (Çetin \& Çetin, 2019; Eskici, 2019).

Sustainable development cannot be achieved only by technological solutions, political arrangements or financial instruments. This requires a consciousness for sustainable development in layers and in terms of all 
social contexts and an education that has the ability to gain said consciousness (UNESCO, 2020). The ability of societies to provide comprehensive and qualified educational opportunities for individuals means that educational activities can be the most familiar and powerful tool for sustainable development. Although sustainability is considered important only from the point of view of development, when we take into account well-developed and developing societies, it can be seen that they invest the most in education and training teachers during educational processes. Understanding of Sustainable Education that has a very important task in guidance towards a sustainable society is accepted all around the world, placed as an action plan in educational policies of countries and, in many cultures, is directly put in the process of being implemented (Öztürk, 2017). In this way, individuals are ensured to acquire a sustainable learning understanding during their studentship years. But in order to gain this understanding to students, first of all, teachers who shall educate them must have an understanding of sustainable learning and be in a constant excitement of learning. It is thought that this may undoubtedly be related to teachers' attitudes towards learning. When we investigate studies conducted on this topic, we do not meet any studies, where these two concepts were studied together in the same place. Therefore, it is thought that being aware of levels of sustainable learning and attitudes of pre-service teachers attitudes towards learning during their educational journey, thus increasing their awarability and positive attitudes for these concepts shall be beneficial both for themselves for their professional lives and also for their students. Based on these considerations, this study was performed in order to examine whether there is a meaningful relationship between attitudes of pre-service teachers studying in higher education institutions towards learning and towards sustainable learning levels.

\section{Purpose of the Study}

The purpose of this study is to examine the relationship between pre-service teachers' attitudes towards learning and sustainable learning levels. For this purpose, answers to the following questions were sought:

1) How are pre-service teachers' attitudes towards learning and sustainable learning levels?

2) Is there a meaningful relationship between pre-service teachers' attitudes towards learning and sustainable learning levels?

3) Do attitudes of pre-service teachers towards learning significantly predict sustainable learning levels?

\section{Method}

\section{Research Model}

This study, which examines the relationship between pre-service teachers' attitudes towards learning and sustainable learning levels, is designed in a correlational survey model from quantitative research models. In the correlational survey model, it is tried to determine whether there is covariance between two or more variables and the degree of covariance (Karasar, 2005).

\section{Population and Sample}

The population of the study consists of 950 pre-service teachers studying at Tekirdag Namik Kemal University during academic year 2020-2021. Samples examined under scope of the study were 428 pre-service teachers, who were chosen by simple random sampling method from above-mentioned population. According to Krejcie and Morgan (1970), this number is sufficient to represent the population with an error ratio of $5 \%$. 253 (59\%) of pre-service teachers, who constitute the sampling group, are females whilst remaining 168 (41\%) are males. 


\section{Data Collection Tools}

During the study, Sustainable Learning Scale developed by Eskici (2019) and Scale for Attitudes Towards Learning developed by Çetin and Çetin (2019) were used. Psychometric characteristics of data collection tools are presented below.

Scale for Attitudes Towards Learning: Scale for Attitudes Towards Learning that is used for measuring attitude levels of pre-service teachers is a likert type scale with five options constituting of 34 Items and 3 subdimensions. Goodness of fit values obtained as a result of confirmatory factor analysis regarding three-factor structure of the scale are as follows: RMSEA, .068; $\chi 2 / \mathrm{df}=1.9$; SRMR=.076; NFI=.94; NNFI=.97; IFI=97; CFI=.97; RFI=.94. Cronbach Alpha Internal Consistency Coefficients calculated for the whole and sub-dimensions of the scale are .94 for the overall scale; .92 for the sub-dimension titled "Effort Towards Learning"; .86 for subdimension titled "Caring"; .84 for sub-dimension titled "Refusal of Learning".

Sustainable Learning Scale: Sustainable Learning Scale, which aims to measure sustainable learning levels of individuals, is a likert type scale with five options constituting of two sub-scales. Behavioral sub-scale of sustainable learning scale consists of 15 items and 3 sub-dimensions whilst cognitive sub-scale consists of 12 items and 2 sub-dimensions. Goodness fit values obtained as a result of confirmatory factor analysis regarding three-factor structure of cognitive sub-scale are as follows: $\chi 2 / \mathrm{df}=3.37, \mathrm{TLI}=.920, \mathrm{CFI}=.933$ and RMSEA $=.056$. Cronbach Alpha Value for "broad and deep learning" sub-dimension of behavioral sub-scale is .85; for sub-dimension titled "learning by adaption", Cronbach Alpha Value is .88; for sub-dimension titled "learning by updates", Cronbach Alpha Value is .90; for behavioral learning sub-scale total, Cronbach Alpha Value is .89. Goodness fit values obtained as a result of confirmatory factor analysis regarding two-factor structure of cognitive sub-scale are as follows: $\chi 2$ /df $=4.70, \mathrm{TLI}=.905, \mathrm{CFI}=.925$ ve $\mathrm{RMSEA}=.071$. Cronbach Alpha Value for sub-dimension titled "Learning for Improvement" of cognitive sub-scale is .88; for subdimension titled "learning for exams", Cronbach Alpha Value is .86; for cognitive learning sub-scale total, Cronbach Alpha Value is .91.

\section{Procedures and Data Analysis}

Data collection tools (Online surveys created on Google Forms Platform) are delivered to e-mails of participators (436 pre-service teachers, who participated in the study on volunteer basis) by the researchers. 428 scales completed by participants were included in the analysis. Data collected from 428 pre-service teachers were analyzed using SPSS 22.0 Software. First, it was examined whether data meet normality assumptions. For this purpose, the skewness and kurtosis values of data set and Q-Q Charts were examined. It is concluded that scores for attitude towards learning (-.50 to 0.20$)$, sustainable learning (cognitive sub-scale) (- .75 to .24$)$ and sustainable learning (behavioral sub-scale) (-.34 to .38) fall in normal distribution limits. George and Mallery (2003) and Kunnan (1998) point out that in case skewness and kurtosis coefficients are in the range of \pm 2 , data shall present normal distribution characteristics. Moreover, it is determined that data are distributed on a linear base, which was expected in Q-Q Charts and realized value of which has a slope of approximately 45 degrees. Therefore, this has shown that data distributions shall be considered normal (Can, 2014). In interpretion of arithmetic average values: 1.00-1.79 range is considered as "very low", 1.80-2.59 range is considered as "low", 2.60-3.39 range is considered as "middle", 3.40-4.19 range is considered as "high" and 4.20-5.00 range is considered as "very high". Descriptive statistics, correlation and regression analysis were used while analyzing the data. Obtained data is analyzed in SPSS 22.0 within computer environment. Significancy levels were tested at .05 level; other significancy levels were also specified and findings are presented in the form of a table in accord with the purpose of this study. While correlation analyse results were being interpreted: .00-.30 range is considered as "low level relationship", .31-.70 range is considered as "moderate level relationship" and .71-1.00 range is considered as "high level relationship". 


\section{Findings}

Relations between arithmetic average, standard deviation and skewness and kurtosis values and scale scores that were used in the study are presented in Table 1.

Table 1. Descriptive statistics of variables and results of correlation analysis

\begin{tabular}{|c|c|c|c|c|c|c|c|}
\hline Variable & Skewness & Kurtosis & $\overline{\mathbf{X}}$ & Sd & 1 & 2 & 3 \\
\hline Attitudes Towards Learning (1) & -.50 & .20 & 4.16 & 0.42 & 1 & & \\
\hline Sustainable Learning (Behavioral) (2) & -.34 & .38 & 3.99 & 0.49 & $.65^{* *}$ & 1 & \\
\hline Sustainable Learning (Cognitive) (3) & -.75 & .24 & 4.40 & 0.41 & $.66^{* *}$ & $.54^{* *}$ & 1 \\
\hline
\end{tabular}

When we examine Table 1, we can see that pre-service teachers' attitudes towards learning $\quad(\overline{\mathrm{X}}=4.16)$ and sustainable learning (behavioral) levels ( $\bar{X}=3.99)$ are at a high levels, while sustainable learning (cognitive) levels $(\overline{\mathrm{X}}=4.40)$ are at very high levels. At the end of correlation analyses, it is observed that there is a positive directioned, moderate level and a meaningful relationship ( $\mathrm{r}=.65 ; \mathrm{p}<.01)$ between pre-service teachers' attitudes towards learning and sustainable learning (behavioral) levels; and there is a moderate level and meaningful relationship $(\mathrm{r}=.66 ; \mathrm{p}<.01)$ between their attitudes towards learning and their sustainable learning levels (cognitive). At the end of correlation analyses, it is observed that there is a positive directioned, moderate level and a meaningful relationship $(\mathrm{r}=.65 ; \mathrm{p}<.01)$ between pre-service teachers' attitudes towards learning and sustainable learning (behavioral) levels; and there is a moderate level and meaningful relationship ( $\mathrm{r}=.66$; $\mathrm{p}<.01$ ) between their attitudes towards learning and their sustainable learning levels (Cognitive). These findings show that as pre-service teachers' attitudes towards learning increase, sustainable learning levels also increase.

After these procedures, in accordance with the main purpose of the study, regression calculations were carried out in order to determine whether score of the scale for attitude towards learning significantly predicts sustainable learning cognitive and behavioral sub-scale scores; and, obtained results are presented in tables below.

Table 2. Regression analysis results between attitude scale towards learning and sustainable learning behavioral subscale

\begin{tabular}{lccccccccc}
\hline Model & $\mathbf{B}$ & $\mathbf{S E}$ & $\boldsymbol{\beta}$ & $\mathbf{t}$ & $\mathbf{p}$ & $\mathbf{R}$ & $\mathbf{R}^{2}$ & $\mathbf{F}$ & $\mathbf{p}$ \\
\hline 1. (constant) & .78 & .18 & & 4.26 & .000 & & & \\
\hline Sustainable Learning (Behavioral) & .77 & .04 & .65 & 17.83 & .000 & .65 & 43 & 317.86 & .000 \\
\hline
\end{tabular}

As shown in Table 2, after completion of regression analysis that were carried out in order to determine whether score of the scale for attitude towards learning significantly predicts sustainable learning behavioral sub-scale scores, it is observed that scale for attitude towards learning is a significant predictor of sustainable learning behavioral sub-scale score $\left(\mathrm{F}_{(1-426)}=317.86, \mathrm{p}<0.001\right)$. It is determined that scale for attitude towards learning meaningfully and statistically explains $43 \%\left(\mathrm{R}^{2}=.43\right.$; $\left.\mathrm{p}<0.001\right)$ of the score variant of sustainable learning behavioral sub-scale. When we examine results of $\mathrm{t}$-test regarding meaningfulness of $(\mathrm{B}=.64)$ coefficient of the predictor variant in Regression Formula, it is seen that scale for attitude towards learning is a meaningful predictor of sustainable learning behavioral sub-scale $(\mathrm{p}<0.001)$.

According to regression analysis results, the equation, which predicts the behavioral sub-scale of sustainable learning, is as follows:

Sustainable learning (behavioral $)=(.77 \times$ attitude towards learning $)+.78$

Table 3. Regression analysis results between attitude scale towards learning and sustainable learning cognitive sub-scale

\begin{tabular}{|c|c|c|c|c|c|c|c|c|c|}
\hline Model & B & SE & $\beta$ & $\mathbf{t}$ & $\mathrm{p}$ & $\mathbf{R}$ & $\mathbf{R}^{2}$ & $\mathbf{F}$ & $\mathrm{p}$ \\
\hline 1. (constant) & 1.74 & .15 & & 11.67 & .000 & & & & \\
\hline Sustainable Learning (Cognitive) & .64 & .04 & .65 & 17.91 & .000 & .66 & 43 & 320.87 & .000 \\
\hline
\end{tabular}


As shown in Table 2, after completion of regression analysis that were carried out in order to determine whether score of the scale for attitude towards learning significantly predicts sustainable learning cognitive and cognitive sub-scale scores, it is observed that scale for attitude towards learning is a significant predictor of sustainable learning cognitive sub-scale score $\left(\mathrm{F}_{(1-426)}=320.87, \mathrm{p}<0.001\right)$. It is determined that scale for attitude towards learning meaningfully and statistically explains $43 \%\left(\mathrm{R}^{2}=.43 ; \mathrm{p}<0.001\right)$ of the score variant of sustainable learning cognitive sub-scale. When we examine results of $t$-test regarding meaningfulness of $(B=.64)$ coefficient of the predictor variant in regression formula, it is seen that scale for attitude towards learning is a meaningful predictor of sustainable learning cognitive sub-scale $(\mathrm{p}<0.001)$.

According to regression analysis results, the equation, which predicts the cognitive sub-scale of sustainable learning, is as follows:

Sustainable learning $($ cognitive $)=(.64 \times$ attitude towards learning $)+1.74$

\section{Discussion, Conclusions and Suggestions}

In this study, the relationship between the attitudes towards learning and sustainable learning levels of 428 pre-service teachers studying at Tekirdag Namik Kemal University in 2020-2021 academic year was examined.

Study findings indicate that pre-service teachers' attitudes towards learning are high. In his study Adigüzel (2014), found that pre-service teachers' attitude towards learning levels were quite high. Similarly, results obtained in the end of studies conducted by Erdamar (2010), Karasakaloğlu (2012) and Aydın (2016) on pre-service teachers support this finding. Being a teacher has a very close relationship with teachinglearning process in a professional sense. Therefore, high attitude of pre-service teachers towards learning can undoubtedly be considered as a positive factor.

Another finding of the study is that pre-service teachers have high level of sustainable learning behavioral sub-scale scores and very high level of sustainable learning cognitive sub-scale scores. In his study on high school students, Eskici (2019) found that students' scores on both sub-scales were at high levels. Although studies on sustainable learning is limited, results of similar studies (Charungkaittikul \& Henschke, 2014; Graham, Berman \& Bellert, 2015) support this finding. It is promising that pre-service teachers have high sustainable learning scores, because teachers are members of the professional group that trains future generations of societies, and as professionals who do the job of teaching, their constant effort to learn is valuable in terms of being able to constantly update their knowledge.

The study found that pre-service teachers' attitudes towards learning had a positive, moderately significant relationship between both behavioral sub-scale of sustainable learning scale and the cognitive subscale of sustainable learning scale. Linear regression analyses found that pre-service teachers' attitudes towards learning predicts sustainable learning levels (behavioral and cognitive) at a significant level. Such a finding obtained in the end of a study is quite meaningful. As a matter of fact, in order for pre-service teachers to adopt a sustainable learning approach, it is expected that their attitude to learning is high and that these attitudes shall have an impact on their sustainable learning levels. Although there is no study published in the literature examining the relationship between these two concepts, results from similar studies support this finding. For example, Adigüzel (2014) found that there was a significant relationship between knowledge, literacy skills of pre-service teachers and their attitudes towards learning. Similarly, Prokop, Leskova, Kubiatko and Diran (2007) found that there is a significant positive relationship between people's attitudes and knowledge levels. 
As a result; (i) Pre-service teachers' attitudes towards learning and their sustainable learning levels are at high levels; (ii) there is a positively directioned, moderate level relationship between pre-service teachers' attitudes towards learning and their sustainable learning levels; (iii) Pre-service teachers' attitudes towards learning significantly predicts their sustainable learning levels (behavioral and cognitive).

This research has some limitations. Study is carried out in a state university in Turkey. Similar studies might be carried out on pre-service teachers studying in different universities and obtained results can be compared. Scales, that are often used as data collection tools in quantitive researches, are used throughout the study. Therefore, obtained data is based on replies of participators to scales and also based on capacity of measuring tools. It is thought that it shall be beneficial to use data collection tools such as observations and interviews that are often used in qualitative researches in future studies together with data collection tools that are often used in quantitive studies by taking limits of this present study into account.

Considering the results obtained in the end of this study, researchers are adviced as follows: (i) similar studies might be carried out in different educational stages (primary schools, secondary schools, high schools); (ii) studies, where similar variants are used on academicians or educators such as teachers, not only on preservice teachers, might be carried out; (iii) further information can be obtained by using qualitative or mixed research methods. Moreover, considering obtained results, these suggestions can be presented to the attention of Implementers: (i) Trainings that aim to improve learning passion of pre-service teachers might be provided in order to boost pre-service teachers' sustainable learning levels and attitudes towards learning; (ii) professional support can be provided to academicians, who shall raise the teachers of the future. 


\section{REFERENCES}

Adıgüzel, A. (2014). Examining the relationship between teacher candidates' attitudes towards learning and information literacy skills in terms of various variables. International Journal of Curriculum and Instructional Studies, 4(7), 13-24.

Anghelache, V. (2013). Determinant factors of students' attitudes toward learning. Procedia-Social and Behavioral Sciences, 93, 478-482.

Aydın, M. (2016). Examination of pre-service science teachers' attitudes towards learning according to some variables. The Journal of International Lingual, Social and Educational Sciences, 2(2), 75-84.

Balcı, A. (2010). Annotated glossary of educational administration terms. Ankara: Pegem Academy Publishing.

Becker, C. U. (2012). Sustainability ethics and sustainability research. Heidelberg: Springer.

Can, A. (2014). Quantitative data analysis in scientific research process with SPSS. Pegem Academy Publishing.

Chang, W. \& Chang, I. (2013). An investigation of students' motivation to learn and learning attitude affect the learning effect: A case study on tourism management students. Anthropologist, 16(3), 457-463.

Charungkaittikul, S., \& Henschke, J. A. (2014). Strategies for developing a sustainable learning society: An analysis of lifelong learning in Thailand. International Review of Education, 60(4), 499-522.

Çetin, Ş., \& Çetin, F. (2019). Attitude towards learning scale development study. Journal of Turkish Educational Sciences, 17(1).

Dash, G., \& Mohan, A. K. (2017). Education for sustainability: perception of teachers and practices in urban primary schools of Mysore. Gyanodaya-The Journal of Progressive Education, 10(2), 9-17.

Domjan, Michael (2004). Basics of conditioning and learning. Ankara: Turkish Psychological Association Publications.

Erdamar, G. (2010). Some variables that affect teacher candidates' study strategies. Journal of Hacettepe University Faculty of Education, 38(38), 82-93.

Eskici, M. (2019). Sustainable learning levels of high school students. Discourse and Communication for Sustainable Education, 10(1), 63-80.

George, D., \& Mallery, P. (2003). SPSS for Windows step by step: Answers to selected exercises. A simple guide and reference, $63,1461-1470$.

Graham, L., Berman, J., \& Bellert, A. (2015). Sustainable learning. Cambridge University Press.

Johnston, P., Everard, M., Santillo, D., \& Robèrt, K. H. (2007). Reclaiming the definition of sustainability. Environmental science and pollution research international, 14(1), 60-66.

Kağıtçıbaşı, C. (1999). New man and people. Social Psychology Series: 1. Istanbul: Evrim Press Publishing and Distribution Publishing.

Karasakaloğlu, N. (2012). The Relationship between reading comprehension and learning and study strategies of prospective elementary school teachers. Educational Sciences: Theory \& Practice, 12(3).

Karasar, N. (2005). Scientific research method. Ankara: Nobel Publishing.

Kazazoğlu, S. (2013). The effect of attitude towards Turkish and English lessons on academic achievement. Education and Science, 38(170). 294-307. 
Kolb, D.A. (1981). Learning styles and disciplinary differences. In A. Chickering (Ed.). The modern American College. San Francisco. CA: Jossey Bass.

Krejcie, R. V., \& Morgan, D. W. (1970). Determining sample size for research activities. Educational and Psychological Measurement, 30(3), 607-610.

Kuşat, N. (2012). Corporate sustainability and its internal elements for sustainable businesses. Journal of Economics \& Administrative Sciences, 14(2).

Marton, F. \& Saljo, R. (1997). Approaches to learning. In Marton, F., Hounsell, D., Entwistle, N.(ed.). The experience of learning. Edinburgh: Scottish Academic Press.

Orhan, U., \& Komşu, U. C. (2016). The effect of self-efficacy perceptions and burnout levels on attitudes towards learning and job satisfaction in academicians. Anadolu University Journal of Social Sciences, 16(3), $1-18$.

Öztürk, M. (2017). Sustainable development-oriented education: Theoretical framework, historical development and practical recommendations. Elementary Education Online, 16(4).

Pashler, H., McDaniel, M., Rohrer, D., \& Bjork, R. (2008). Learning styles: Concepts and evidence. Psychological science in the public interest, 9(3), 105-119.

Pehlivan, K. B. (2010). A study on prospective teachers' learning styles and attitudes towards the teaching profession. Elementary Education Online, 9(2), 749-763.

Prokop, P., Lešková, A., Kubiatko, M., \& Diran, C. (2007). Slovakian students' knowledge of and attitudes toward biotechnology. International Journal of Science Education, 29(7), 895-907.

Salami, S. O. (2010). Emotional intelligence, self efficacy, psychological well-being and students' attitudes: Implications for quality education. European Journal of Educational Studies, 2(3), 247- 257.

Samuelsson, I. P., \& Park, E. (2017). How to educate children for sustainable learning and for a sustainable world. International Journal of Early Childhood, 49(3), 273-285.

Senemoğlu, N. (2012). Development, learning and teaching: From theory to practice. Ankara: Pegem Academy Publishing.

Thomas, I. (2009). Critical thinking, transformative learning, sustainable education, and problem-based learning in universities. Journal of Transformative Education, 7(3), 245-264.

UNESCO. (2020). One Planet, One Ocean. https://en.unesco.org/themes/one-planet-one-ocean

Yang, H., Farn, C. (2005). An investigation the factors affecting MIS student burn-out in technical-vocational college. Computers in Human Behaviour, 21, 917-932.

Zhu, Y., Zhang, J. H., Au, W., \& Yates, G. (2020). University students' online learning attitudes and continuous intention to undertake online courses: A self-regulated learning perspective. Educational Technology Research and Development, 1-35. 